Article

\title{
Isolation of a Highly Efficient Antigenic-Protein- Degrading Bacillus amyloliquefaciens and Assessment of Its Safety
}

\author{
Yang Li, Baozhu Guo, Chong Li, Weiwei Wang, Zhengke Wu, Guohua Liu and Huiyi Cai * \\ The Key Laboratory of Feed Biotechnology of Ministry of Agriculture, National Engineering Research Center of \\ Biological Feed, Feed Research Institute, Chinese Academy of Agricultural Sciences, No.12 Zhongguancun \\ South Street, Haidian District, Beijing 100081, China; liyang8906@163.com (Y.L.); guobaozhu957@163.com (B.G.); \\ lichong@caas.cn (C.L.); dbnywzw@163.com (W.W.); wzk199107@163.com (Z.W.); liuguohua@caas.cn (G.L.) \\ * Correspondence: caihuiyi@caas.cn; Tel.: +86-10-8210-6077
}

Received: 22 June 2020; Accepted: 3 July 2020; Published: 6 July 2020

check for updates

Simple Summary: Soybean meal (SBM), a byproduct of soybean oil extraction, is a commonly used dietary protein in the poultry and swine feed industries because of its high quality protein and relatively well-balanced amino acids. However, major antigenic proteins in SBM, glycinin and $\beta$-conglycinin, can trigger allergic reactions, including intestine villus atrophy and other malabsorption syndromes, in newborn animals. Microbial fermentation is considered an economically viable processing technique to reduce the content of antigenic proteins, and improve the nutritional quality of SBM. The kind of microorganism used in fermentation is one of the major factors affecting the nutritional value of SBM. In this study, a highly efficient Bacillus. amyloliquefaciens strain was successfully isolated with convenient and effective plate tests, and used in a fermentation experiment. Fermentation with B. amyloliquefaciens for $24 \mathrm{~h}$ effectively degraded the glycinin and $\beta$-conglycinin in SBM, significantly improved the crude protein content and acid soluble protein concentration, and increased the total amino acid content. Furthermore, B. amyloliquefaciens had no adverse effects on animal health. These results indicate that the B. amyloliquefaciens strain isolated in this study is safe for animal use and can be widely used in SBM fermentation.

\begin{abstract}
The aims of this study were to screen and isolate a highly efficient strain from the rumen of a cow that can degrade the antigenic soy proteins in soybean meal (SBM) and improve the nutritional value of SBM by fermenting it with this strain. The safety of this strain was investigated with an acute oral toxicity test. A Bacillus amyloliquefaciens strain was successfully screened with plate tests and fermentation. After solid state fermentation of SBM with B. amyloliquefaciens for $24 \mathrm{~h}$, the amounts of glycinin and $\beta$-conglycinin, two major antigenic proteins in SBM, decreased by $92.32 \%$ and $85.05 \%$, respectively. The crude protein content in the fermented soybean meal (FSBM) increased by $17.54 \%$ compared with that in SBM. Notably, the trichloroacetic-acid-soluble protein (TCA-SP) content, particularly small peptides and free amino acids, was 9.97-fold higher in FSBM than in SBM. The in vitro dry matter digestibility and digestible energy of SBM increased from $62.91 \%$ to $72.52 \%$ and from $10.42 \mathrm{MJ} / \mathrm{kg}$ to $13.37 \mathrm{MJ} / \mathrm{kg}$ (dry matter basis), respectively, after fermentation. The acute oral toxicity test suggested that the strain exerted no harmful effects on the relative organ weights, the morphological tissue structure, or the health of mice. These results indicate that the B. amyloliquefaciens strain isolated in this study is a safe strain for animals, and could be used to improve the nutritional quality of SBM by solid-state fermentation.
\end{abstract}

Keywords: B. amyloliquefaciens; fermentation; soybean meal; antigenic protein; safety assessment 


\section{Introduction}

Soybean meal (SBM), a co-product of soybean oil extraction from soybeans, is commonly used in the poultry and swine industries because of its high quality protein and relatively well-balanced amino acid content [1]. However, a variety of antinutritional factors (ANFs) in SBM, such as oligosaccharides, lectin, and allergenic antigens, hinder the digestion and absorption of its nutrients by animals [2-4]. Glycinin and $\beta$-conglycinin are the two main types of allergenic soybean proteins, accounting for about $30 \%$ and $40 \%$ of the total protein in SBM, respectively [5]. Previous studies have demonstrated that glycinin damages the intestinal morphology, with effects such as intestinal atrophy and necrosis, and causes malabsorption syndrome in animals [6-8]. $\beta$-Conglycinin causes hypersensitive immune response and negatively affects the growth performance of animals $[9,10]$. These drawbacks limit the extensive use of SBM in animal feeds. Therefore, the development of processing techniques that remove the harmful and antinutritional factors of SBM may produce a high-quality protein with functional properties [11].

Fermentation is considered an economically viable processing technique in which microorganisms are used to increase the protein concentration, reduce the content of ANFs, and enhance the nutritional value of SBM [12]. It has been documented that the apparent ileal digestibility of the dry matter, nitrogen and energy in fermented soybean meal (FSBM) is similar to that of fish meal [13]. Bacteria and fungi are the two main types of microorganisms used to ferment animal feed or feed ingredients. Bacillus spp. have a stronger capacity to resist heat and acid [14], and secrete many kinds of extracellular enzymes, including non-starch polysacchrides degrading enzymes and proteinase, and are therefore commonly used in bacteria-based fermentation [15]. Seo and Cho reported that the contents of glycinin and $\beta$-conglycinin in SBM decreased by $70 \%$ and $50 \%$, respectively, after fermentation with B. subtilis KCCM11438P for $24 \mathrm{~h}$ [16]. Teng et al. reported that fermentation of SBM with B. subtilis SB102 degraded its large antigenic proteins, and increased the small-size proteins and the contents of some essential amino acids compared with those in unfermented SBM [17]. In addition to Bacillus spp., Lactobacillus spp. are also frequently used in solid state fermentation to produce organic acids and reduce the $\mathrm{pH}$ of SBM. Chi and Cho demonstrated that Lactobacillus spp. significantly reduced the $\mathrm{pH}$ of SBM, but did not decompose protein-based ANFs other than trypsin inhibitors after solid state fermentation for $36 \mathrm{~h}$ [18]. Fungal fermentation with several species of the genus Aspergillus, such as A. niger and A. oryzae, caused much smaller increases in small proteins and smaller reductions in larger antigenic proteins in SBM than bacterial fermentation [15]. The efficiency of fermentation in improving nutritional value of SBM depends on growth rate, extracellular enzymes and its activities of microorganisms involved [18]. Therefore, it is vital to choose a highly efficient allergen-degrading microorganism for the production of FSBM with high nutritional quality.

The glycinin and $\beta$-conglycinin in SBM does not cause hypersensitive immune response in gastrointestinal tract or affect the growth performance of ruminants as they do in pre-ruminant animals and nonruminant animals because the rumen contains a mixed community of microbes [19] that can inactivate and degrade glycinin and $\beta$-conglycinin [20]. About $12 \%$ to $38 \%$ of the total bacterial population in rumen are strains with proteolytic activities [21], so the rumen is an ideal place to select an appropriate bacterium for the decomposition of glycinin and $\beta$-conglycinin in SBM. In previous studies, target bacteria were successfully isolated from a preserved vegetable [22], traditional fermented soy foods [23], and animal intestinal tracts [24]. However, to our knowledge, no research has used a strain derived from the rumen flora to ferment SBM. The selected bacteria have previously been used to ferment SBM directly, and animal experiments have been conducted without considering the safety of the strain in these experiments. However, some bacteria may produce hemolysin, which is considered a virulence-related factor that impairs the intestinal epithelial cells $[25,26]$. Therefore, the objective of this study was to screen a highly efficient bacterial strain in a cow rumen with which to degrade the antigenic proteins in SBM, and to improve the nutritional quality of SBM by fermentation with this strain. The safety of this bacterium was evaluated with an acute oral toxicity test. 


\section{Materials and Methods}

\subsection{Isolation of Bacterial Strain}

Rumen liquid was collected from a fistulated cow feeding at the Experimental Nankou Base of Chinese Academy of Agricultural Science (Beijing, China), and was filtered through double cheesecloth. An aliquot $(1 \mathrm{~mL})$ of the rumen liquid was homogenized in $9 \mathrm{~mL}$ of $8.5 \%(w / v)$ sterile salt water, and then incubated at $80{ }^{\circ} \mathrm{C}$ for $20 \mathrm{~min}$ to destroy other microbial cell [23,27]. Defatted milk agar pates were inoculated with this homogenate for bacterial culture by gradient dilution $\left(10^{-2}-10^{-7}\right)$. These inoculated plates were cultured in a biochemical incubator at $37^{\circ} \mathrm{C}$ for $24 \mathrm{~h}$. After incubation, strains were selected according to the size of the transparent zone around colonies (data not shown). Six strains were isolated for a further screening experiment, and denoted 'GYL'. Two strains of B. subtilis stored previously in our laboratory, designated BSD2 and CICC21237, were used as the positive controls.

\subsection{SBM and Medium Preparation}

SBM was purchased from the Hopefull Grain \& Oil Co. Ltd. (Langfang, Hebei, China). Agar plates containing antigenic protein (glycinin or $\beta$-conglycinin), starch, or xylan were used to determine the protease, amylase, and xylanase activities of the strains, respectively. The antigenic proteins were extracted from SBM according to the method reported by Liu et al. [28] and Deak et al. [29], with minor modification. Briefly, about $15 \mathrm{~g}$ of defatted soy flour was extracted with $0.03 \mathrm{M}$ Tris- $\mathrm{HCl}(\mathrm{pH} \mathrm{8.5)}$ in a 15:1 (w/v) buffer-to-flour ratio. The resulting slurry was stirred $200 \mathrm{r} / \mathrm{min}$ for $1 \mathrm{~h}$ at $45^{\circ} \mathrm{C}$ and centrifuged at $9000 \times g$ for $40 \mathrm{~min}$ at $4{ }^{\circ} \mathrm{C}$. After centrifugation, the supernatant was discarded and the precipitate was extracted two more times. The appropriate amount of solid $\mathrm{NaHSO}_{3}$ was added to the supernatant to achieve a concentration of $10 \mathrm{mM} \mathrm{NaHSO}_{3}$ and the $\mathrm{pH}$ was adjusted to 6.4 with $2 \mathrm{M} \mathrm{HCl}$. The slurry was stored at $4{ }^{\circ} \mathrm{C}$ overnight and then centrifuged at $6500 \times \mathrm{g}$ for $20 \mathrm{~min}$ at $4{ }^{\circ} \mathrm{C}$. The glycinin-rich fraction was thus obtained. Solid $\mathrm{NaCl}$ was added to the supernatant to a final concentration of $0.25 \mathrm{M}$ and the $\mathrm{pH}$ adjusted to 5.5 with $2 \mathrm{M} \mathrm{HCl}$. The slurry stirred at $45^{\circ} \mathrm{C}$ and $200 \mathrm{r} / \mathrm{min}$ for $30 \mathrm{~min}$, and then centrifuged at $9000 \times \mathrm{g}$ for $40 \mathrm{~min}$ at $4{ }^{\circ} \mathrm{C}$. The supernatant was diluted two-fold with pure water and adjusted to $\mathrm{pH} 4.8$ with $2 \mathrm{M} \mathrm{HCl}$. The $\beta$-conglycinin-rich fraction was obtained after centrifugation at $6500 \times \mathrm{g}$ for $20 \mathrm{~min}$ at $4{ }^{\circ} \mathrm{C}$. The total precipitate was dissolved in pure water to prepare protein plates. Starch agar plates were prepared by adding $1 \mathrm{~g}$ of corn starch and $1.5 \mathrm{~g}$ of agar to $100 \mathrm{~mL}$ of Luria-Bertani (LB) medium (1\% tryptone, $1 \% \mathrm{NaCl}$, and $0.5 \%$ yeast extract). Xylan agar plates were prepared by mixing $0.3 \mathrm{~g}$ of xylan and $1.5 \mathrm{~g}$ of agar to $100 \mathrm{~mL}$ of LB. To prepare defatted milk agar plates, $5 \mathrm{~g}$ of defatted milk (Yili, Inner Mongolia, China) and $1.5 \mathrm{~g}$ of agar were added to $100 \mathrm{~mL}$ of LB. All plates were autoclaved for $21 \mathrm{~min}$ at $121{ }^{\circ} \mathrm{C}$.

\subsection{Solid State Fermentation}

The SBM for fermentation was sieved through a 10 mesh screen. The inocula of eight bacteria were prepared by incubating a single colony in LB medium at $37^{\circ} \mathrm{C}$ for $21 \mathrm{~h}$. SBM (20 g) was mixed with distilled water to $50 \%(w / v)$ in a $150 \mathrm{~mL}$ conical flask and inoculated with fresh inoculum in a $5 \%$ ratio $(w / v)$. Each mixture was incubated at $37^{\circ} \mathrm{C}$ for $24 \mathrm{~h}$, each treatment was performed in triplicate. After fermentation, the FSBM samples were dried at $60^{\circ} \mathrm{C}$ for $4 \mathrm{~h}$, ground, and passed through a 60-mesh screen. The fermented powder samples were stored at $4{ }^{\circ} \mathrm{C}$ before analysis.

\subsection{Chemical Composition of FSBM}

The crude protein content was estimated with a combustion analyzer (Dumatherm, Gerhardt, Germany) using ethylenediaminetetraacetic acid as the calibration standard. The content of trichloroacetic acid-soluble protein (TCA-SP) in SBM or FSBM was measured with trichloroacetic acid (TCA) according to the China National Standard (GB/T 22492-2008). Briefly, $1 \mathrm{~g}$ of sample was mixed with $20 \mathrm{~mL}$ of $15 \%(w / v)$ TCA, and the slurry was stirred at room temperature for 5 min and centrifuged 
at $4000 \times g$ for $10 \mathrm{~min}$. The supernatant was collected, and the nitrogen content of the supernatant was determined with an automatic Kjeldahl Nitrogen Analyzer (FOSS, Hillerod, Denmark).

The contents of glycinin and $\beta$-conglycinin in the SBM or FSBM were analyzed using competitive enzyme-linked immunosorbent assay (ELISA) kits (Longkefangzhou Bio-Engineering Technology Company, Beijing, China). The total amino acid content was extracted with $6 \mathrm{M} \mathrm{HCl}$ and measured with an automatic amino acid analyzer (Hitachi L-8900, Tokyo, Japan).

\subsection{Protein Extract and SDS-PAGE}

The soluble proteins in SBM and FSBM were extracted as previously described by Yang et al. [1]. The soluble protein concentrations were quantified with Bio-Rad Protein Assay Kit (Bio-Rad, Hercules, CA, USA), according to the manufacturer's protocol. The fractions of soluble protein in the SBM and FSBM were detected with $12 \%$ polyacrylamide separating gels containing $0.1 \%$ SDS in Tris-glycine buffer. About $15 \mu \mathrm{L}$ of total denatured soluble protein sample was loaded into a well. The extracted soluble protein sample was concentrated at $80 \mathrm{~V}$ for $30 \mathrm{~min}$ and separated at $120 \mathrm{~V}$ for $60 \mathrm{~min}$. The gel was stained with Coomassie Brilliant Blue R-250 (Bio-Rad) for $45 \mathrm{~min}$, and destained with 7\% (v/v) acetic acid.

\subsection{Biochemical Characteristics and Molecular Identification of the Candidate Strain}

The biochemical characteristics of the strain GYL6 were determined using a commercial kit (Hopebio Co., Ltd., Qingdao, China) according to the manufacturer's instructions. The genomic DNA of strain GYL6 was extracted with the Ezup Genomic DNA Extraction Kit (Sangon Biotech Co., Ltd., Shanghai, China), according to the manufacturer's protocol. The full-length sequence of 16S rRNA of strain GYL6 was amplified by polymerase chain reaction (PCR) with the primers 27F (5'-AGAGTTTGATCMTGGCTCAG-3') and 1492R (5'-TAGGG TTACCTTACGACTT-3') (Sangon Biotech Co., Ltd.). The gyrase B (gyrB) gene of strain GYL6 was amplified with PCR using primers UP1F (5'-GAAGTCATCATGACCGTTCTGCA-3') and UP2R (5'-AGCAGGGTACGGATGTGC GAGCC-3') (Sangon Biotech Co., Ltd.). The PCR amplification was carried out in a $25 \mu \mathrm{L}$ reaction mixture containing $25 \mathrm{ng}$ of template DNA, $0.5 \mu \mathrm{L}$ of each primer, $1 \mu \mathrm{L}$ PCR premix, $0.2 \mu \mathrm{L}$ Taq mix, $2.5 \mu \mathrm{L}$ buffer and PCR-grade water to adjust the volume. The PCR reaction was conducted under the following conditions, $5 \mathrm{~min}$ at $94{ }^{\circ} \mathrm{C}$, followed by 35 cycles at $94{ }^{\circ} \mathrm{C}$ for $30 \mathrm{~s}, 54{ }^{\circ} \mathrm{C}$ for $30 \mathrm{~s}$, and $72{ }^{\circ} \mathrm{C}$ for $90 \mathrm{~s}$, with final extension for $10 \mathrm{~min}$ at $72{ }^{\circ} \mathrm{C}$. Amplified PCR products were analyzed by agarose gel (1\%) electrophoresis. After gel extraction, the products were purified by SanPrep pillar PCR purification kit (Sangon Biotech Co., Ltd.). Finally, the PCR products of strain GYL6 were sequenced on Illumina Miseq platform (Illumina Inc., San Diego, CA, USA) provided by Sangon Biotech Co., Ltd. The ribosomal sequences obtained were compared with those released in GenBank (National Center for Biotechnology Information, Bethesda, MD, USA) database using the Nucleotide Basic Local Alignment Search Tool program.

\subsection{In vitro Digestibility}

The in vitro digestibility of dry matter and digestible energy of FSBM and SBM were assayed with a computer-controlled simulated digestion system (CCSDS), which was developed and designed by Zhao et al. and Chen et al. [30,31] to simulate the gastrointestinal digestion system of monogastric animals. The machine automatically finishes the in vitro digestion process, including the gastric, upper- and lower-intestinal digestion, when the procedural instructions are followed. In brief, $2 \mathrm{~g}$ of FSBM or SBM and $20 \mathrm{~mL}$ simulated gastric fluid ( $1500 \mathrm{U} / \mathrm{mL}$ pepsin, $\mathrm{pH} 2.0)$ was placed in the dialysis tubing within the digestion chamber, and then the gastric buffer solution $\left(\mathrm{pH} 2.0,41^{\circ} \mathrm{C}\right)$ was pumped $(120 \mathrm{~mL} / \mathrm{min})$ into the digestion chambers and circulated for $4 \mathrm{~h}$. After gastric digestion, the upper-intestinal digestion was performed, $2 \mathrm{~mL}$ of concentrated simulated small-intestinal fluid (401.46 U/mL amylase, $49.28 \mathrm{U} / \mathrm{mL}$ trypsin, $11.31 \mathrm{U} / \mathrm{mL}$ chymotrypsin, $\mathrm{pH} 6.50$ ) was injected into the digestion chamber, followed by injection of the upper-small-intestinal buffer solution $(120 \mathrm{~mL} / \mathrm{min}$; 
$\mathrm{pH} 6.50,41^{\circ} \mathrm{C}$ ) and circulation for $7.5 \mathrm{~h}$. Finally, the lower-small-intestinal buffer solution ( $\mathrm{pH} 8.0$, $41^{\circ} \mathrm{C}$ ) was pumped into the digestion chambers and circulated for $7.5 \mathrm{~h}$. During in vitro digestion, a temperature of $41{ }^{\circ} \mathrm{C}$ was maintained in a shaking incubator set to $180 \mathrm{rpm} / \mathrm{min}$, to allow the sample and digestive fluid to mix adequately. After the simulated digestion was completed, the undigested residues were transferred to a preweighed vessel and dried overnight at $65^{\circ} \mathrm{C}$ and then at $105^{\circ} \mathrm{C}$ for $5 \mathrm{~h}$ until a constant weight was achieved. The vitro digestibility of dry matter and the digestible energy were calculated with the following equations:

In digestibility of dry matter $(\%)=$ (initial dry matter content - residual dry matter content $)$ $\times 100 \% /$ initial dry matter content

In vitro digestible energy $(\mathrm{MJ} / \mathrm{kg})=($ initial dry matter gross energy - residual dry matter gross energy)/(initial dry matter content $\times 1000$ )

\subsection{Safety Assessment of the Candidate Strain}

In the preliminary experiment, the candidate strain showed no harmful effect on the health of mice, so an acute oral toxicity test was performed with a maximal tolerated dose. Twenty healthy specific-pathogen-free (SPF) grade male C57BL/6J mice (7-8 weeks old) were obtained from Sibeifu (Beijing, China) Biotechnology Co., Ltd. (Beijing, China), certificate of conformity no. SCXK (Jing) 2016-0002). The mice were randomly divided into two groups based on body weight and housed five per cage. The room for mouse growth was maintained at a temperature of $23 \pm 2{ }^{\circ} \mathrm{C}$, a relative humidity of $50-55 \%$, and a $12 \mathrm{~h}$ light-dark cycle. The mice were fed ad libitum and had free access to drinking water. After acclimation for 7 days, the mice in the treatment group were administered $0.4 \mathrm{~mL}$ of bacterial suspension $\left(1.0 \times 10^{9} \mathrm{CFU} / \mathrm{mL}\right)$ by oral gavage daily for 7 consecutive days, which was approximately equivalent to $2.0 \times 10^{10} \mathrm{CFU}$ per kg bodyweight, and the control group of mice was administered the same amount of physiological saline. After gavage, clinical observations were carried out and recorded daily, including any changes in skin, eyes, or fur, the occurrence of secretions or excretions, and autonomic activity, such as lacrimation, piloerection, and unusual respiratory patterns. Two weeks after gavage, the mice were killed by cervical dislocation. Their spleens, livers, and intestinal tracts were subjected to necropsy and histopathological examination. The spleens, livers, and hearts were also immediately weighed and the organ ratios calculated. The present study was approved by the Animal Ethics Committee of Chinese Academy of Agricultural Science (code number: AEC-CAAS-20190721; approval date: 21 July 2019) and was conducted in accordance with the principles outlined in the National Institutes of Health (NIH) Guide for the Care and Use of Laboratory Animals.

\subsection{Statistical Analysis}

All statistical analyses were performed with the SPSS 19.0 software (SPSS Inc., Chicago, IL, USA). The data on crude protein, TCA-SP, and antigenic proteins were analyzed with one-way ANOVA and Duncan's post-hoc test. The comparison of two means was tested using Student's $t$-test. Difference were considered significant at $p<0.05$.

\section{Results}

\subsection{Screening Strains for SBM Fermentation}

In a preliminary experiment, six candidate strains were successfully isolated from the rumen of cow on defatted milk agar plates for further screening. As shown in Table 1, the results of rescreening showed that five strains (GYL2, GYL3, GYL5, GYL6 and BSD2) produced transparent zones with greater diameters on the glycinin agar plates than the other strains, indicating their greater ability to degrade the glycinin. The transparent zone diameters of all strains except GYL1 and GYL4 on the $\beta$-conglycinin agar plates, indicated their capacity to degrade $\beta$-conglycinin. GYL4, GYL5, GYL6, and 21237 exhibited 
amylase activity on the starch agar plates, whereas of these eight strains, only GYL5 and GYL6 displayed xylanase activity. Strain GYL6 showed higher hydrolysis transparent zone diameter/colony diameter (HD/CD) ratios on these kinds of agar plates than GYL5. Therefore, strain GYL6 was selected as the candidate strain for further study. To confirm the suitable strain, solid state fermentation was conducted to verify the results of the agar plate analyses.

Table 1. Size of the transparent zone formed by the actions of enzyme of candidate strains.

\begin{tabular}{|c|c|c|c|c|c|c|c|c|c|c|c|c|}
\hline \multirow[b]{2}{*}{ Strain } & \multicolumn{3}{|c|}{ Protease $^{a}$} & \multicolumn{3}{|c|}{ Protease $^{b}$} & \multicolumn{3}{|c|}{ Amylase } & \multicolumn{3}{|c|}{ Xylanase } \\
\hline & $\begin{array}{l}\mathrm{HD}^{\mathrm{c}} \\
(\mathrm{cm})\end{array}$ & $\begin{array}{l}\mathrm{CD}^{\mathrm{d}} \\
(\mathrm{cm})\end{array}$ & HD/CD & $\underset{(\mathrm{cm})}{\mathrm{HD}}$ & $\begin{array}{c}\mathrm{CD} \\
(\mathrm{cm})\end{array}$ & HD/CD & $\begin{array}{l}\mathrm{HD} \\
(\mathrm{cm})\end{array}$ & $\begin{array}{c}\mathrm{CD} \\
(\mathrm{cm})\end{array}$ & HD/CD & $\begin{array}{l}\text { HD } \\
(\mathrm{cm})\end{array}$ & $\begin{array}{c}\mathrm{CD} \\
(\mathrm{cm})\end{array}$ & $\mathrm{HD} / \mathrm{CD}$ \\
\hline GYL6 & 2.70 & 1.00 & 2.70 & 2.70 & 1.10 & 2.45 & 2.00 & 1.10 & 1.82 & 1.73 & 1.23 & 1.41 \\
\hline GYL5 & 2.83 & 2.30 & 1.21 & 2.43 & 1.47 & 1.66 & 2.73 & 2.43 & 1.12 & 2.73 & 2.42 & 1.12 \\
\hline 21237 & - & - & - & 1.13 & 0.57 & 2.00 & 1.27 & 0.67 & 1.9 & - & - & - \\
\hline BSD2 & 1.70 & 0.60 & 2.83 & 1.47 & 0.60 & 2.44 & - & - & - & - & - & - \\
\hline GYL4 & - & - & - & - & - & - & 1.13 & 0.87 & 1.31 & - & - & - \\
\hline GYL3 & 1.67 & 0.53 & 3.13 & 1.43 & 0.53 & 2.53 & - & - & - & - & - & - \\
\hline GYL2 & 1.63 & 0.53 & 3.06 & 1.37 & 0.53 & 2.56 & - & - & - & - & - & - \\
\hline GYL1 & - & - & - & - & - & - & - & - & - & - & - & - \\
\hline
\end{tabular}

Table 2 shows the effects of fermentation with all the strains used in this study on the allergenic protein, crude protein, and TCA-SP contents in SBM. ELISAs showed that the maximal degradation of glycinin and $\beta$-conglycinin was reduced from $179.43 \mathrm{mg} / \mathrm{g}$ to $13.78 \mathrm{mg} / \mathrm{g}$ and from $135.83 \mathrm{mg} / \mathrm{g}$ to $20.30 \mathrm{mg} / \mathrm{g}$, respectively, after fermentation with strain GYL6. Solid state fermentation with GYL2, GYL3, BSD2, and GYL6 for $24 \mathrm{~h}$ increased the content of TCA-SP in FSBM to 18.05\%, 18.53\%, 17.24\%, $21.39 \%$, respectively $(p<0.05)$. Notably, the content of TCA-SP was approximately 11 -fold higher in FSBM than in SBM, after fermentation with GYL6. Fermentation with strain GYL6 increased the contents of TCA-SP and crude protein significantly more than fermentation with other strains $(p<0.05)$.

Table 2. Effects of fermentation with different candidate strains on the contents of TCA-SP, antigenic protein, and crude protein in SBM.

\begin{tabular}{|c|c|c|c|c|c|c|}
\hline \multirow[b]{2}{*}{ Items } & \multirow[b]{2}{*}{$\begin{array}{c}\text { TCA-SP, } \\
\%\end{array}$} & \multirow[b]{2}{*}{$\begin{array}{c}\text { Crude Protein, } \\
\%\end{array}$} & \multicolumn{2}{|c|}{ Glycinin } & \multicolumn{2}{|c|}{$\beta$-Conglycinin } \\
\hline & & & $\begin{array}{l}\text { Content, } \\
\mathrm{mg} / \mathrm{g}\end{array}$ & $\underset{\%}{\text { Degradation }^{1}}{ }^{1}$ & $\begin{array}{l}\text { Content, } \\
\mathrm{mg} / \mathrm{g}\end{array}$ & $\begin{array}{c}\text { Degradation, } \\
\%\end{array}$ \\
\hline SBM & $1.95 \mathrm{~g}$ & $46.92^{c}$ & $179.43^{a}$ & - & $135.83^{a}$ & - \\
\hline GYL6 $^{2}$ & $21.39^{a}$ & $55.15^{\mathrm{a}}$ & $13.78^{\mathrm{e}}$ & 92.32 & $20.30^{e}$ & 85.05 \\
\hline GYL5 & $10.12^{d}$ & $54.55^{a, b}$ & $131.95^{b}$ & 26.46 & $56.46^{b}$ & 58.43 \\
\hline 21237 & $8.34^{\mathrm{e}}$ & $53.05^{b}$ & $147.83^{b}$ & 17.61 & $61.81^{b}$ & 54.49 \\
\hline BSD2 & $17.24^{\mathrm{b}}$ & $54.29 \mathrm{ab}$ & $32.92^{\mathrm{d}}$ & 81.65 & $31.55^{\mathrm{d}}$ & 76.77 \\
\hline GYL4 & $11.78^{\mathrm{c}}$ & $53.95^{b}$ & $116.40^{c}$ & 35.13 & $51.52^{\mathrm{c}}$ & 62.07 \\
\hline GYL3 & $18.53^{\mathrm{b}}$ & $53.45^{b}$ & $29.89^{d}$ & 83.34 & $28.89^{d}$ & 78.73 \\
\hline GYL2 & $18.05^{\mathrm{b}}$ & $53.74^{b}$ & $27.21^{d}$ & 84.83 & $27.65^{\mathrm{d}}$ & 79.64 \\
\hline GYL1 & $6.77^{\mathrm{f}}$ & $53.64^{b}$ & $139.24^{b}$ & 22.39 & $58.95^{b}$ & 56.60 \\
\hline SEM & 1.27 & 0.52 & 7.89 & - & 7.12 & - \\
\hline$p$-value & $<0.01$ & $<0.01$ & $<0.01$ & - & $<0.01$ & - \\
\hline
\end{tabular}

${ }^{1}$ Degradation rate $=($ antigenic protein content in SBM -antigenic protein content in FSBM $)$ /antigenic protein content in SBM $\times 100 \%$; $^{2}$ GYL (no.) means FSBM produced by this strain. Different subscript letters indicate significant differences in the column at $p<0.05$.

SDS-PAGE was conducted to further analyze the effects of fermentation with different bacterial strains on the SBM protein profile. As shown in Figure 1, SBM displayed all the subunit bands of the SBM antigenic protein (Figure 1, lane 9), including three subunits $\left(\alpha, \alpha^{\prime}, \beta\right)$ of $\beta$-conglycinin, and the two subunits (acidic and basic) of glycinin. fermentation with gyl6 successfully degraded the $\alpha, \alpha^{\prime}$, and $\beta$ subunits of $\beta$-conglycinin and the acidic subunit of glycinin (Figure 1 , line 8 ). Most of 
the macromolecular proteins in SBM was below $34 \mathrm{kDa}$ after fermentation with GYL6. By contrast, other strains, such as GYL1, GYL4, GYL5, and 21237 (Figure 1, lane 1, lane 5, lane 7, and lane 3, respectively), had weaker abilities to reduce content of the antigenic proteins in SBM, as illustrated by the ELISA analysis. Therefore, strain GYL6 was used in subsequent experiments.

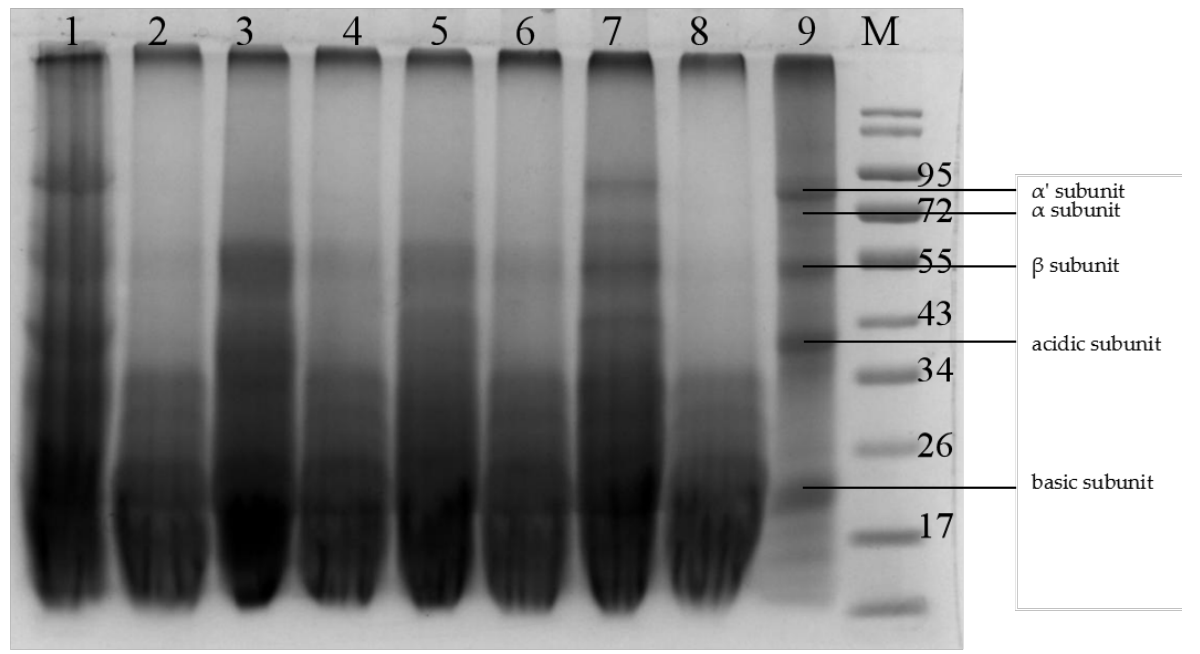

Figure 1. Protein electrophoresis analysis of SBM and FSBM produced by different strains. Lane 1, GYL1 fermented SBM; lane 2, GYL2 fermented SBM; lane 3, CICC21237 fermented SBM; lane 4, GYL3 fermented SBM; lane 5, GYL4 fermented SBM; lane 6, BSD2 fermented SBM; lane 7, GYL5 fermented SBM; lane 8, GYL6 fermented SBM; lane 9, unfermented SBM; M, protein molecular weight marker.

\subsection{Identification of Candidate Strain}

The morphological and biochemical characteristics of GYL 6 were compared with other reference B.amyloliquefaciens reported by other research (Table 3), which suggested that the strain GYL 6 belonged to B. amyloliquefaciens. The full 16S rRNA sequence (Figure S1) of strain GYL6 shared 100\% identity with B. amyloliquefaciens strain SX 16 NA (GenBank accession MT052665.1). Meanwhile, the complete gyrase B (gyrB) sequence (Figure S2) of strain GYL6 shared 100\% identity with that of B. amyloliquefaciens ZJU1 (GenBank accession CP041691.1). Therefore, based on the above characteristics, strain GYL6 was identified as B. amyloliquefaciens.

Table 3. The morphological and biochemical characteristics of GYL 6 and other B. amyloliquefaciens.

\begin{tabular}{|c|c|c|c|}
\hline Items & GYL6 & B. amyloliquefaciens $S 20^{\text {a }}$ [32] & B. amyloliquefaciens $L N 2^{b}$ \\
\hline Cell shape & Rod & Rod & Rod \\
\hline Gram staining & + & + & + \\
\hline D-Glucose & + & + & + \\
\hline D-Xylose & + & + & + \\
\hline L-Rhamnose & - & No detected & - \\
\hline D-Mannitol & + & + & + \\
\hline L-Arabinose & + & No detected & + \\
\hline Maltose & + & + & + \\
\hline Sucrose & + & + & + \\
\hline Lactose & + & No detected & + \\
\hline Malonate & - & No detected & No detected \\
\hline Starch & + & + & + \\
\hline Citrate & + & + & + \\
\hline Nitrate reduction test & + & + & No detected \\
\hline VP-reaction & - & + & No detected \\
\hline
\end{tabular}

"+" represents positive reaction; " -" represents negative reaction; ${ }^{\mathrm{a}}$ Chen et al.; ${ }^{\mathrm{b}}$ Lee et al. 


\subsection{Effect of Fermentation with B. amyloliquefaciens on the Amino Acid Composition of SBM}

Table 4 shows the total amino acids detected in SBM and FSBM. The total amino acids content increased by $6.57 \%$ after fermentation with B. amyloliquefaciens for $24 \mathrm{~h}$. The contents of some essential amino acids, including valine, methionine, phenylalanine, and histidine, were significantly increased in FSBM by $10.68 \%, 14.71 \%, 13.31 \%$, and 16.13\%, respectively. Among the nonessential amino acids, the contents of alanine, proline, cysteine, and glutamic in FSBM increased by 10.33\%, 14.81\%, 16.67\%, and $20.21 \%$, respectively, compared with those in unfermented SBM. However, the contents of arginine and serine were significantly lower in $\operatorname{FSBM}(p<0.05)$.

Table 4. Amino acid composition of SBM fermented for $24 \mathrm{~h}$ with B. amyloliquefaciens.

\begin{tabular}{ccccc}
\hline Items & SBM & FSBM & SEM & $p$-Value \\
\hline Essential amino acid & & & & \\
Arg & 3.36 & 2.95 & 0.01 & $<0.01$ \\
His & 1.24 & 1.44 & 0.01 & $<0.01$ \\
Lys & 3.10 & 3.13 & 0.02 & 0.21 \\
Met & 0.68 & 0.78 & 0.03 & 0.03 \\
Thr & 1.83 & 1.90 & 0.02 & 0.04 \\
Ile & 2.29 & 2.28 & 0.03 & 0.77 \\
Leu & 3.76 & 3.82 & 0.06 & 0.34 \\
Phe & 2.48 & 2.81 & 0.02 & $<0.01$ \\
Val & 2.34 & 2.59 & 0.03 & $<0.01$ \\
Cys & & & & \\
Gly & 0.66 & 0.77 & 0.01 & $<0.01$ \\
Ala & 2.04 & 2.19 & 0.01 & $<0.01$ \\
Tyr & 2.13 & 2.35 & 0.06 & 0.02 \\
Asp & 1.55 & 1.73 & 0.06 & 0.06 \\
Ser & 5.51 & 5.67 & 0.01 & $<0.01$ \\
Pro & 2.41 & 2.13 & 0.02 & $<0.01$ \\
Glu & 2.43 & 2.79 & 0.03 & $<0.01$ \\
Total & 8.46 & 10.17 & 0.16 & $<0.01$ \\
& 46.40 & 49.45 & 0.47 & 0.02 \\
\hline
\end{tabular}

3.4. Effect of Fermentation with B. amyloliquefaciens on In Vitro Digestibility of SBM

The results for the in vitro digestibility of SBM and FSBM are presented in Figure 2. Both the in vitro dry matter digestibility and the digestible energy increased significantly from $62.91 \%$ to $72.52 \%$ and from $10.42 \mathrm{MJ} / \mathrm{kg}$ to $13.37 \mathrm{MJ} / \mathrm{kg}$ (dry matter basis), respectively, after fermentation with B. amyloliquefaciens for $24 \mathrm{~h}(p<0.05)$.
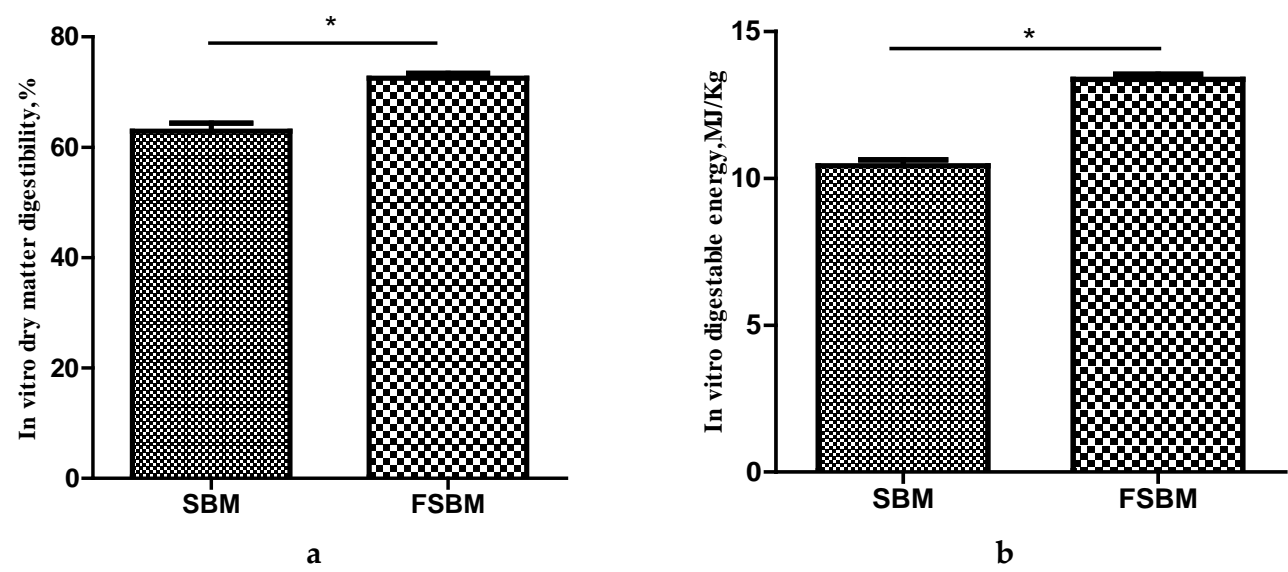

Figure 2. In vitro digestibility of SBM and FSBM. (a) In vitro dry matter digestibility of SBM and FSBM; (b) In vitro digestible energy of SBM and FSBM. * indicates significant differences at $p<0.05$. 


\subsection{Effect of Administration of B. amyloliquefaciens on Bodyweight and Organ Indices of Mice}

After the oral administration of B. amyloliquefaciens to mice for 7 days and their observation for 14 days, there were no deaths in either the control group or experimental group. No obvious symptoms of toxicity were detected in skin, fur, or eyes. No changes in other physiological activities were observed immediately after administration of $B$. amyloliquefaciens or during the posttreatment period in two groups. Neither of the mice showed any visible abnormality of the visceral organs of the mice during necropsy. All the mice grew well. As shown in Table 5, the final weight of experimental group slightly higher than that of control group, but not significantly so at $p<0.05$ level. The organ indices of the mice, including of the heart, liver, and spleen, did not differ significantly between the control and treatment groups $(p>0.05)$.

Table 5. Effect of administration of B. amyloliquefaciens on bodyweight and organ indices of mice.

\begin{tabular}{ccccccc}
\hline \multirow{2}{*}{ Items } & \multicolumn{2}{c}{ Body Weight } & \multicolumn{2}{c}{ Organ Index of Mice (\%) } & \multirow{2}{*}{ Mortality Rate (\%) } \\
\cline { 2 - 5 } & $\begin{array}{c}\text { Initial } \\
\text { Weight (g) }\end{array}$ & $\begin{array}{c}\text { Final } \\
\text { Weight (g) }\end{array}$ & Heart & Liver & Spleen & \\
\hline control group & 23.20 & 26.07 & 0.54 & 4.26 & 0.31 & 0 \\
treatment group & 23.20 & 26.73 & 0.53 & 4.15 & 0.32 & 0 \\
SEM & 0.21 & 0.30 & 0.01 & 0.05 & 0.01 & - \\
$p$-value & 1.00 & 0.16 & 0.45 & 0.20 & 0.47 & - \\
\hline
\end{tabular}

3.6. Effect of Oral Administration of B. amyloliquefaciens on Intestinal Morphological Structure and Hispathology of Mice

Table 6 shows the villus height (VH), crypt depth (CD), and VH/CD ratio in the duodenum, jejunum, and ileum of the treated mice. The treatment group had higher $\mathrm{VH}$ in the duodenum and ileum, and a higher $\mathrm{VH} / \mathrm{CD}$ ratio in the jejunum and ileum than the control group $(p<0.05)$. There were no significant differences in CD in the duodenum or ileum between the two treatment groups.

Histopathological examination of the tissues of the two treatment groups showed no visible pathological changes in the livers or spleens of the mice, and no abnormal macroscopic structures of the livers or spleens. There was no swelling, necrosis, degeneration, inflammatory changes, or cell infiltration in the pathological sections of the livers or spleens, (Figures 3 and 4), respectively.

Table 6. Effect of oral administration with B. amyloliquefaciens on the intestinal morphological structures of mice.

\begin{tabular}{clcccc}
\hline \multirow{2}{*}{ Items } & Control Group & Experimental Group & SEM & $p$-Value \\
\hline \multirow{4}{*}{ Duodenum } & Villus height (VH) & 381.09 & 438.77 & 12.06 & 0.01 \\
& Crypt depth (CD) & 72.80 & 85.85 & 8.05 & 0.32 \\
& VH: CD ratio & 5.57 & 5.26 & 0.54 & 0.78 \\
\hline \multirow{4}{*}{ Jejunum } & Villus height (VH) & 261.17 & 280.91 & 4.01 & 0.23 \\
& Crypt depth (CD) & 94.91 & 79.27 & 5.71 & 0.04 \\
& VH: CD ratio & 2.75 & 3.61 & 0.29 & 0.03 \\
\hline \multirow{4}{*}{ Ileum } & Villus height (VH) & 225.42 & 303.00 & 5.4 & $<0.01$ \\
& Crypt depth (CD) & 75.66 & 83.29 & 3.28 & 0.27 \\
& VH: CD ratio & 2.97 & 3.64 & 0.11 & $<0.01$ \\
\hline
\end{tabular}




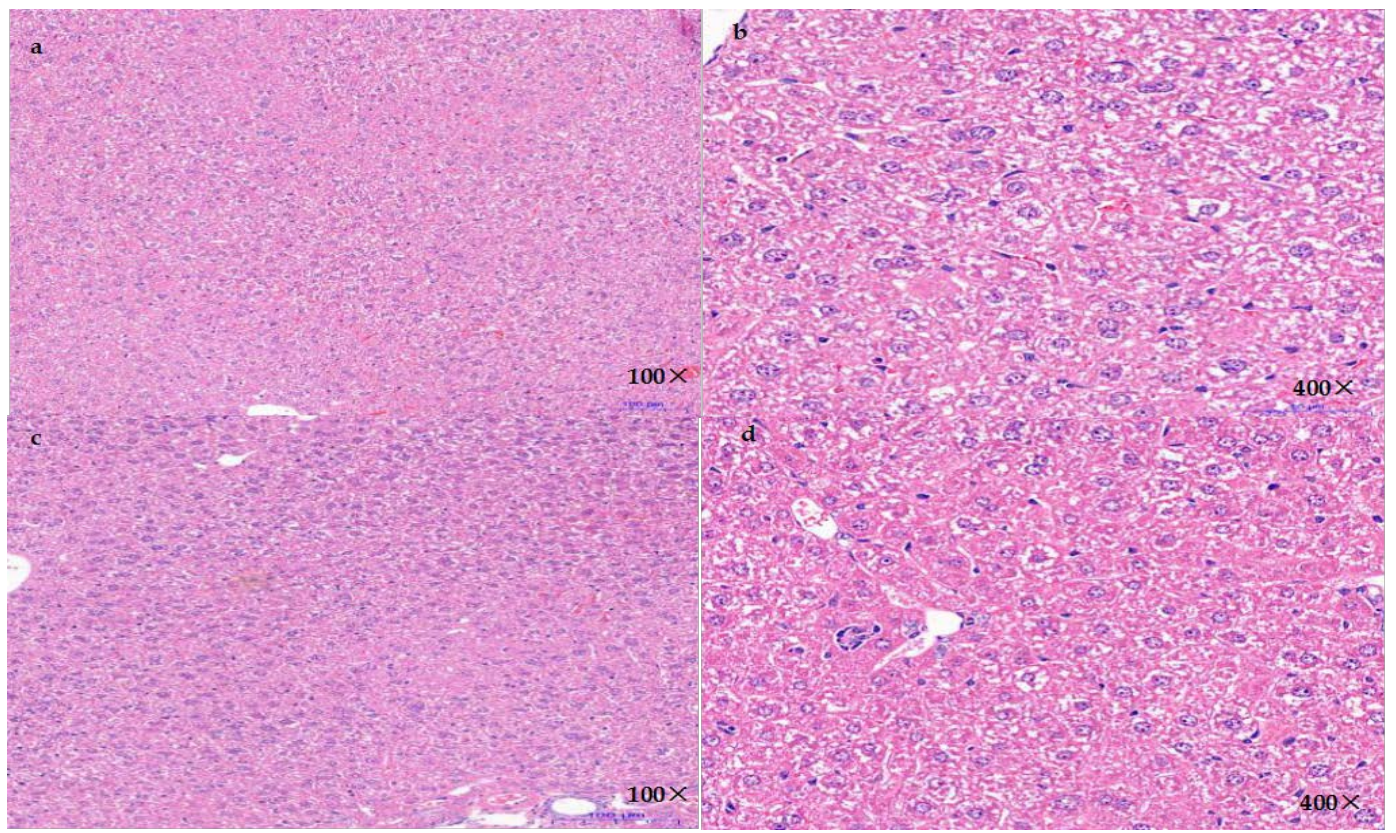

Figure 3. Pathological sections of liver tissues from mice. (a) control group(magnification 100x); (b) control group(magnification 400×); (c) experimental group(magnification 100×); (d) experimental group(magnification $400 \times$ ).

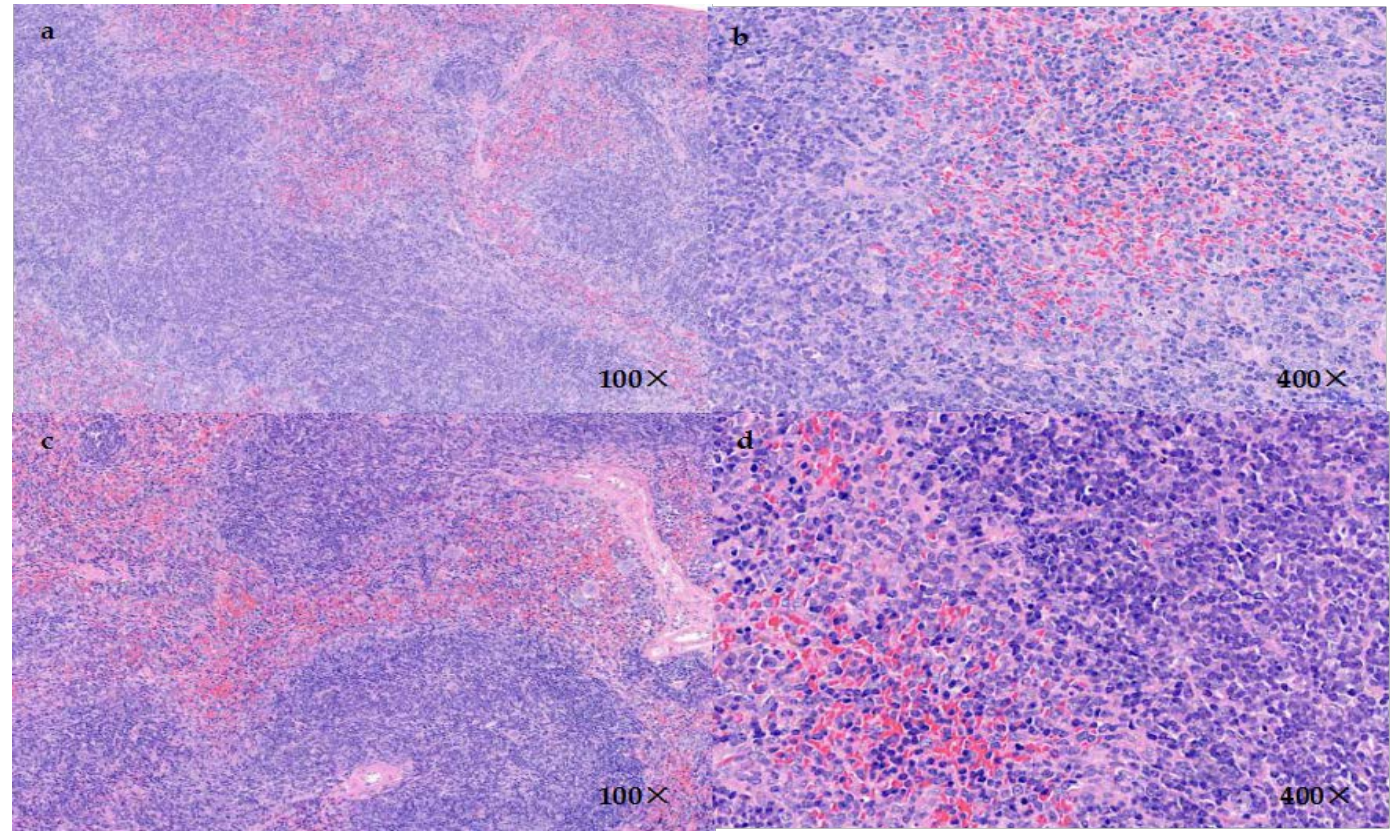

Figure 4. Pathological sections of spleen tissues from mice. (a) control group (magnification 100×); (b) control group (magnification 400×); (c) experimental group(magnification 100×); (d) experimental group(magnification $400 \times$ ).

\section{Discussion}

Fermented feed has the advantages of improving the feed quality and gut ecology of animals compared with supplementation with feed with additives, such as probiotics, prebiotics, synbiotics, and enzymes [34]. The kind of microorganisms used in this fermentation is one of the major factors affecting the nutritional value of feed and feed ingredients. Bacillus ssp. are the predominant fermentative microorganisms used to ferment feed. In previous studies, Bacillus ssp. were used to ferment SBM from 
traditional fermented soy food [22,23], and aquatic animals, such as shrimp guts [35] and grass carp intestine [24], respectively. They were screened with soymilk, xylan, and starch agar plate methods. However, the ability of the target strains to degrade glycinin and $\beta$-conglycinin could not be determined indirectly with these agar plate tests. In the present study, glycinin and $\beta$-conglycinin were extracted from SBM and used as the sole substrates upon which to culture the candidate strains. The abilities of the candidate strains to degrade the antigenic proteins were compared directly by measuring the diameters of the transparent zones on the culture plates. Among these eight isolates, strain GYL6 showed higher proteinase, xylanase, and amylase activities than other seven strains on agar plates. The results of solid state fermentation with these eight strains confirmed that strain GYL6 was the most efficient strain. It eliminated most glycinin and $\beta$-conglycinin from the SBM, and significantly increased its content of crude protein and TCA-SP. These results were consistent with the results of agar plate test method. These findings show that plate tests are an effective and convenient method to screen suitable strains in future studies.

It is recommended that gyr B gene sequences be used, as well as 16S rRNA gene sequences, to identify bacterial strains, because the high genetic similarity of Bacillus spp. make them difficult to discriminate. A previous study demonstrated that the gyrB gene has a faster rate of molecular evolution than 16S rRNA and more precisely identifies bacterial strains [36]. In the current study, strain GYL6 was identified as B. amyloliquefaciens using both $16 \mathrm{~S}$ rRNA and gyrB sequences.

This study clearly demonstrates that $92.32 \%$ of glycinin and $85.05 \%$ of $\beta$-conglycinin were removed after fermentation with B. amyloliquefaciens for $24 \mathrm{~h}$. These results are similar to those reported by Zhang et al., who found that $84.77 \%$ of glycinin and $87.07 \%$ of $\beta$-conglycinin were degraded after fermentation with B. subtilis BS12 for $24 \mathrm{~h}$ [22]. By contrast, only $42 \%$ of glycinin and $70 \%$ of $\beta$-conglycinin were eliminated by another strain of B. subtilis [16]. Under optimum fermentation conditions (temperature $40{ }^{\circ} \mathrm{C}$, time $48 \mathrm{~h}$ and $4 \%$ inoculum $(w / v)$ ), the glycinin in SBM fermented with B. sanfensis or B. stratosphericus decreased by only $62.0 \%$ or $41.1 \%$, respectively [35]. These differences in the degradation of the antigenic proteins in SBM indicates that the B. amyloliquefaciens isolated in the present study has a stronger capacity for protein hydrolysis. Recently, we found that $B$. amyloliquefaciens secretes many extracellular hydrolytic enzymes during its fermentation of SBM, including not only serine protease and acid protease, but also endoglucanase, acetylxylan esterase, and catalase, which broke down cell-wall polymers and facilitated the degradation of antigenic protein (unpublished data). The reduction of antigenic soybean proteins increases the digestibility of nutrients and improves the growth performance of animals [9,37]. Previous studies have demonstrated that FSM enhances intestinal barrier function [38,39], attenuates the intestinal mucosal immune response [9], and reduces the incidence of diarrhea, which are related to the reduction in the antigenic proteins of SBM.

Several reports had demonstrated that fermentation with different Bacillus spp. substantially increases the crude protein content of SBM $[17,18,40]$. In the present study, crude protein increased significantly by $17.54 \%$ after fermentation with B. amyloliquefaciens for $24 \mathrm{~h}$. The increase in crude protein may be attributable to the loss of carbohydrates, which might be used as substrates in the growth and reproduction of bacteria. At the same time, the content of TCA-SP, which consists of small peptides with 2-20 residues, was approximately 11-fold higher in FSBM than in SBM. A previous study demonstrated that dipeptides and tripeptides are directly absorbed by the animal intestinal tract, and that amino acids in the form of small peptides are transported more rapidly than their constituent amino acids in free form [22]. Our analysis of the in vitro digestibility suggested that the fermentation of SBM with B. amyloliquefaciens enhanced its nutritional value and it was digested easily by digestive enzymes.

In present study, SBM fermented with B. amyloliquefaciens significantly increased the total amino acids by $6.57 \%$ and changed its amino acids composition. The essential amino acids, including valine, methionine, phenylalanine, and histidine, were 10-17\% higher in FSBM than in SBM. These results are partly consistent with the findings of Medeiros et al., who reported that the contents of lysine, valine, histidine, and phenylalanine increased by $15-19 \%$ in FSBM fermented with B. amyloliquefaciens. 
Among these essential amino acids, methionine, the first limiting amino acid in the corn-soybean meal diet, significantly influences the energy metabolism, immune function [41] and growth performance of animals [42]. Valine is a functionally essential branched-chain amino acid and the fourth limiting amino acid, which also plays an important role in improving growth performance and enhancing the immunity of animals [43]. Therefore, these increases in some essential amino acids could reduce the currently necessary supplementation of animal feed with synthetic amino acids. However, the amino acid composition of SBM is altered differently when it was fermented with different microorganisms. In the present study, we found that the lysine content remained unchanged, whereas methionine increased in FSBM. These results are identical to those reported by Chi and Cho [18], but contrary to findings of Gao et al. [35], who demonstrated that the content of methionine was more than two fold higher in FSBM than in SBM. Hassaana et al. reported that except for serine and histidine, all the amino acids in SBM increased significantly after fermentation with Saccharomyces cerevisiae [44], whereas in another study, the essential amino acid profile of SBM was unchanged after fermentation with A. oryzae GB-107 [45]. The discrepancies in these finding may be attributable to the proteinase profiles and secretion abilities of the microorganism used [15]. These findings also indicate that the suitable microorganism for fermentation must be selected in accordance with the nutritional requirements of final fermented feed product.

Today, many researchers and companies use strains from different sources to directly ferment feed, without considering the potential risks of the isolated strains. Previous studies have reported that some Bacillus spp., including B. cereus, B. coagulans, and B. weihenstephanesis, produce both enterotoxins and emetic toxins, which are recognized as the main causes of food poisoning and other non-gastrointestinal infections [46]. Therefore, it is important to comprehensively evaluate the safety of a bacterial strain before it is incorporated into animal feed [26].In vitro and in vivo method are the main approach to evaluate the safety of probiotics. In vivo method includes detecting the known toxin gene, using cultured cell line to evaluate adhesion, invasion, and cytotoxicity of probiotics $[47,48]$. In vivo studies are the preferred approach to substantiate in vitro analysis of safety [49]. However, no specific guidelines are currently in place for assessing probiotics, but acute oral toxicity testing is the fundamental assay for assessing the safety of novel microbial strains intended as feed additives or for use in feed production, and has been applied in many studies [14,50]. For an acute toxicity study, mice were chosen because they are considered the most sensitive laboratory animals [47]. Based on the results of our preliminary experiment, acute oral toxicity testing was performed by intragastrically administering B. amyloliquefaciens to mice at a maximal dose of $2.0 \times 10^{10} \mathrm{CFU} / \mathrm{kg}$ BW for 7 consecutive days in this study. At the end of this experiment, all the mice were healthy, with no noticeable abnormal behavior or changes in activities. There were no significant changes in the relative weight of the major organs of mice. Relative organ weight has long been recognized as an important indicator of chemical organ damage [46,51]. Hyperplastic changes, congestion, edema, and visceral atrophy also reflect the damage caused by poisonous substances [51]. In the present study, there were no differences in the relative organ weights or morphological structures of the tissues after the administration of B. amyloliquefaciens, indicating that the strain had no adverse effects on the health status of mice and can be considered safe for fermented feed production.

\section{Conclusions}

In conclusion, a highly efficient $B$. amyloliquefaciens strain was successfully isolated from the rumen of a cow with plate tests and fermentation. Fermentation with B. amyloliquefaciens effectively degraded the glycinin and $\beta$-conglycinin in SBM, significantly improved the crude protein content and acid soluble protein concentration, and increased the total amino acid content. Our results also show that the intragastric administration of B. amyloliquefaciens at the maximal dose had no adverse effects on animal health. These results indicate that the B. amyloliquefaciens strain isolated in this study is safe for animal use and can be widely applied to SBM fermentation. 
Supplementary Materials: The following are available online at http://www.mdpi.com/2076-2615/10/7/1144/s1, Figure S1: The 16S rDNA sequences amplified from B. amyloliquefaciens, Figure S2: The gyrase B sequences amplified from B. amyloliquefaciens.

Author Contributions: Conceptualization, Y.L.; methodology, Y.L. and Z.W.; software, Y.L., C.L., and W.W.; validation, Y.L.; formal analysis, Y.L. and Z.W.; investigation, Y.L. and B.G.; resources, H.C.; data curation, H.C.; writing —original draft preparation, Y.L.; writing—review and editing, Y.L., H.C. and G.L.; visualization, H.C.; supervision, H.C. and G.L.; project administration, H.C. and G.L.; funding acquisition, H.C. All authors have read and agreed to the published version of the manuscript.

Funding: This research was funded by China Agricultural Research System (CARS-42).

Conflicts of Interest: The authors declare no conflict of interest.

\section{References}

1. Yang, A.-S.; Zuo, L.-L.; Cheng, Y.-F.; Wu, Z.; Li, X.; Tong, P.; Chen, H. Degradation of major allergens and allergenicity reduction of soybean meal through solid-state fermentation with microorganisms. Food Funct. 2018, 9, 1899-1909. [CrossRef] [PubMed]

2. Perez-Maldonado, R.-A.; Mannion, P.-F.; Farrell, D.-J. Effects of heat treatment on the nutritional value of raw soybean selected for low trypsin inhibitor activity. Br. Poult. Sci. 2003, 44, 299-308. [CrossRef] [PubMed]

3. Batal, A.-B.; Parsons, C.-M. Utilization of different soy products as affected by age in chicks. Poult. Sci. 2003, 82, 454-462. [CrossRef] [PubMed]

4. Dunsford, B.R.; Knabe, D.A.; Haensly, W.E. Effect of dietary soybean meal on the microscopic anatomy of the small intestine in the early-weaned pig. J. Anim. Sci. 1989, 67, 1855-1864. [CrossRef]

5. Maruyama, N.; Sato, R.; Wada, Y.; Matsumura, Y.; Goto, H.; Okuda, E.; Nakagawa, S.; Utsumi, S. Structure-physicochemical function relationships of soybean $\beta$-conglycinin constituent subunits. J. Agric. Food Chem. 1999, 47, 5278-5284. [CrossRef]

6. Zhao, Y.; Qin, G.; Sun, Z.; Zhang, X.; Bao, N.; Wang, T.; Zhang, B.; Zhang, B.; Zhu, D.; Sun, L. Disappearance of immunoreactive glycinin and beta-conglycinin in the digestive tract of piglets. Arch. Anim. Nutr. 2008, 62, 322-330. [CrossRef]

7. Zhao, Y.; Qin, G.; Sun, Z.; Wang, T.; Zhang, B. Effects of glycinin and $\beta$-conglycinin on enterocyte apoptosis, proliferation and migration of piglets. Food Agric. Immunol. 2010, 21, 209-218. [CrossRef]

8. Li, D.-F.; Nelssen, J.-L.; Reddy, P.-G.; Blecha, F.; Klemm, R.; Goodband, R.-D. Interrelationship between hypersensitivity to soybean proteins and growth performance in early-weaned pigs. J. Anim. Sci. 1991, 69, 4062-4069. [CrossRef]

9. Zhu, J.; Gao, M.; Zhang, R.; Sun, Z.; Wang, C.; Yang, F.; Huang, T.; Qu, S.; Zhao, L.; Li, Y.; et al. Effects of soybean meal fermented by L. plantarum, B. subtilis and S. cerevisieae on growth, immune function and intestinal morphology in weaned piglets. Microb. Cell Fact. 2017, 16, 191. [CrossRef]

10. Chen, F.; Hao, Y.; Piao, X.-S.; Ma, X.; Wu, G.-Y.; Qiao, S.-Y.; Li, D.-F.; Wang, J.-J. Soybean-derived beta-conglycinin affects proteome expression in pig intestinal cells in vivo and in vitro. J. Anim. Sci. 2011, 89, 188-202. [CrossRef]

11. Li, J.; Zhou, R.; Ren, Z.; Fan, Y.; Hu, S.; Zhuo, C.; Deng, Z. Improvement of protein quality and degradation of allergen in soybean meal fermented by Neurospora crassa. LWT 2019, 101, 220-228. [CrossRef]

12. Hamidoghli, A.; Won, S.; Farris, N.-W.; Bae, J.; Choi, W.; Yun, H.; Bai, S.-C. Solid state fermented plant protein sources as fish meal replacers in whiteleg shrimp Litopaeneus vannamei. Anim. Feed Sci. Tech. 2020, 264, 114474. [CrossRef]

13. Jeong, J.-S.; Park, J.-W.; Lee, S.-I.; Kim, I.-H. Apparent ileal digestibility of nutrients and amino acids in soybean meal, fish meal, spray-dried plasma protein and fermented soybean meal to weaned pigs. Anim. Sci. J. 2016, 87, 697-702. [CrossRef] [PubMed]

14. Gu, S.; Zhao, L.; Wu, Y.; Li, S.; Sun, J.; Huang, J.; Li, D. Potential probiotic attributes of a new strain of Bacillus coagulans CGMCC 9951 isolated from healthy piglet feces. World J. Microb. Biot. 2015, 31, 851-863. [CrossRef] [PubMed]

15. Mukherjee, R.; Chakraborty, R.; Dutta, A. Role of fermentation in improving nutritional quality of soybean meal-A review. Asian Austral. J. Anim. 2016, 29, 1523-1529. [CrossRef]

16. Seo, S.; Cho, S. Changes in allergenic and antinutritional protein profiles of soybean meal during solid-state fermentation with Bacillus subtilis. LWT 2016, 70, 208-212. [CrossRef] 
17. Teng, D.; Gao, M.; Yang, Y.; Liu, B.; Tian, Z.; Wang, J. Bio-modification of soybean meal with Bacillus subtilis or Aspergillus oryzae. Biocatal. Agric. Biotechnol. 2012, 1, 32-38. [CrossRef]

18. Chi, C.; Cho, S. Improvement of bioactivity of soybean meal by solid-state fermentation with Bacillus amyloliquefaciens versus Lactobacillus spp. and Saccharomyces cerevisiae. LWT Food Sci. Technol. 2016, 68, 619-625. [CrossRef]

19. Tukur, H.-M.; Lallès, J.-P.; Mathis, C.; Caugant, I.; Toullec, R. Digestion of soybean globulins, glycinin, $\alpha$-conglycinin and $\beta$-conglycinin in the preruminant and the ruminant calf. Can. J. Anim. Sci. 1993, 73, 891-905. [CrossRef]

20. Mir, P.-S.; Burton, J.H.; Wilkie, B.N.; van de Voort, F.-R. Reduction of $\beta$-conglycinin antigenicity and rate of acid-pepsin proteolysis of proteins in extruded or rumen fluid-treated soybean meal. Can. J. Anim. Sci. 1989, 69, 727-734. [CrossRef]

21. Cotta, M.-A.; Hespell, R.-B. Proteolytic activity of the ruminal bacterium butyrivibrio fibrisolvens. Appl. Environ. Microbiol. 1986, 52, 51-58. [CrossRef]

22. Zhang, Y.; Shi, C.-Y.; Wang, C.; Lu, Z.-Q.; Wang, F.-Q.; Feng, J.; Wang, Y.-Z. Effect of soybean meal fermented with Bacillus subtilis BS12 on growth performance and small intestinal immune status of piglets. Food Agric. Immunol. 2018, 29, 133-146. [CrossRef]

23. Wongputtisin, P.; Khanongnuch, C.; Khongbantad, W.; Niamsup, P.; Lumyong, S. Screening and selection of Bacillus spp. For fermented corticate soybean meal production. J. Appl. Microbiol. 2012, 113, 798-806. [CrossRef]

24. Medeiros, S.; Xie, J.; Dyce, P.-W.; Cai, H.-Y.; DeLange, K.; Zhang, H.; Li, J. Isolation of bacteria from fermented food and grass carp intestine and their efficiencies in improving nutrient value of soybean meal in solid state fermentation. J. Anim. Sci. Biotechnol. 2018, 9, 29. [CrossRef]

25. Liu, J.; Fang, C.; Jiang, Y.; Yan, R. Characterization of a Hemolysin Gene ytjA from Bacillus subtilis. Curr. Microbiol. 2009, 58, 642-647. [CrossRef]

26. AlGburi, A.; Volski, A.; Cugini, C.; Walsh, E.-M.; Chistyakov, V.-A.; Mazanko, M.-S.; Bren, A.-B.; Dicks, L.-M.-T.; Chikindas, M.-L. Safety properties and probiotic potential of Bacillus subtilis KATMIRA1933 and Bacillus amyloliquefaciens B-1895. Adv. Microbiol. 2016, 06, 432-452. [CrossRef]

27. Chantawannakul, P.; Oncharoen, A.; Klanbut, K.; Chukeatiroteb, E.; Lumyonga, S. Characterization of proteases of Bacillus subtilis strain 38 isolated from traditionally fermented soybean in Northern Thailand. Sci. Asia 2002, 28, 241-245. [CrossRef]

28. Liu, C.; Wang, H.; Cui, Z.; He, X.; Wang, X.; Zeng, X.; Ma, H. Optimization of extraction and isolation for $11 S$ and 7S globulins of soybean seed storage protein. Food Chem. 2007, 102, 1310-1316. [CrossRef]

29. Deak, N.-A.; Murphy, P.-A.; Johnson, L.-A. Effects of $\mathrm{NaCl}$ Concentration on Salting-in and Dilution During Salting-out on Soy Protein Fractionation. J. Food Sci. 2006, 71, C247-C254. [CrossRef]

30. Chen, L.; Gao, L.-X.; Huang, Q.-H.; Lu, Q.-P.; Sa, R.-N.; Zhang, H.-F. Prediction of digestible energy of feed ingredients for growing pigs using a computer-controlled simulated digestion system1. J. Anim. Sci. 2014, 92, 3887-3894. [CrossRef]

31. Zhao, F.; Ren, L.-Q.; Mi, B.-M.; Tan, H.-Z.; Zhao, J.-T.; Li, H.; Zhang, H.-F.; Zhang, Z.-Y. Developing a computer-controlled simulated digestion system to predict the concentration of metabolizable energy of feedstuffs for rooster1. J. Anim. Sci. 2014, 92, 1537-1547. [CrossRef] [PubMed]

32. Chen, D.; Liu, X.; Li, C.; Tian, W.; Shen, Q.; Shen, B. Isolation of Bacillus amyloliquefaciens S20 and its application in control of eggplant bacterial wilt. J. Environ. Manag. 2014, 137, 120-127. [CrossRef] [PubMed]

33. Lee, A.; Cheng, K.; Liu, J. Isolation and characterization of a Bacillus amyloliquefaciens strain with zearalenone removal ability and its probiotic potential. PLOS ONE 2017, 12, e0182220. [CrossRef]

34. Dai, Z.; Cui, L.; Li, J.; Wang, B.; Guo, L.; Wu, Z.; Zhu, W.; Wu, G. Fermentation techniques in feed production. Anim. Agric. 2020, 407-429. [CrossRef]

35. Gao, S.; Pan, L.; Zhang, M. Screening of bacterial strains from the gut of Pacific White Shrimp (Litopenaeus vannamei) and their efficiencies in improving the fermentation of soybean meal. FEMS Microbiol. Lett. 2020, 367. [CrossRef] [PubMed]

36. Larsen, N.; Thorsen, L.; Kpikpi, E.-N.; Stuer-Lauridsen, B.; Cantor, M.-D.; Nielsen, B.; Brockmann, E.; Derkx, P.-M.-F.; Jespersen, L. Characterization of Bacillus spp. Strains for use as probiotic additives in pig feed. Appl. Microbiol. Biot. 2014, 98, 1105-1118. [CrossRef] 
37. Zhu, J.; Gao, M.; Song, X.; Zhao, L.; Li, Y.; Hao, Z. Changes in bacterial diversity and composition in the faeces and colon of weaned piglets after feeding fermented soybean meal. J. Med. Microbiol. 2018, 67, 1181-1190. [CrossRef]

38. Zhang, Y.; Chen, S.; Zong, X.; Wang, C.; Shi, C.; Wang, F.; Wang, Y.; Lu, Z. Peptides derived from fermented soybean meal suppresses intestinal inflammation and enhances epithelial barrier function in piglets. Food Agric. Immunol. 2020, 31, 120-135. [CrossRef]

39. Roh, S.; Carroll, J.-A.; Kim, S.-W. Effects of fermented soybean meal on innate immunity-related gene expressions in nursery pigs acutely challenged with lipopolysaccharides. Anim. Sci. J. 2015, 86, 508-516. [CrossRef]

40. Zheng, L.; Li, D.; Li, Z.-L.; Kang, L.-N.; Jiang, Y.-Y.; Liu, X.-Y.; Chi, Y.-P.; Li, Y.-Q.; Wang, J.-H. Effects of Bacillus fermentation on the protein microstructure and anti-nutritional factors of soybean meal. Lett. Appl. Microbiol. 2017, 65, 520-526. [CrossRef] [PubMed]

41. Swain, B.-K.; Johri, T.-S. Effect of supplemental methionine, choline and their combinations on the performance and immune response of broilers. Br. Poult. Sci. 2000, 41, 83-88. [CrossRef] [PubMed]

42. Huyghebaert, G.; Pack, M. Effects of dietary protein content, addition of nonessential amino acids and dietary methionine to cysteine balance on responses to dietary sulphur-containing amino acids in broilers. Br. Poult. Sci. 1996, 37, 623-639. [CrossRef] [PubMed]

43. Edmonds, M.S.; Gonyou, H.W.; Baker, D.H. Effect of excess levels of methionine, tryptophan, arginine, lysine or threonine on growth and dietary choice in the pig. J. Anim. Sci. 1987, 65, 179-185. [CrossRef] [PubMed]

44. Hassaan, M.-S.; Soltan, M.-A.; Abdel-Moez, A.-M. Nutritive value of soybean meal after solid state fermentation with Saccharomyces cerevisiae for Nile tilapia, Oreochromis niloticus. Anim. Feed Sci. Tech. 2015, 201, 89-98. [CrossRef]

45. Lim, J.; Park, B.; Kim, M.; Rhee, M.; Park, S.; Yun, H. Acute Oral Toxicity and Pathogenicity of a Potential Probiotic Bacillus sp. A9184 Isolated from Soybean Paste. Toxicol. Res. 2004, 20, 359-363.

46. Nithya, V.; Muthukumar, S.-P.; Halami, P.-M. Safety Assessment of Bacillus licheniformis Me1 Isolated from Milk for Probiotic Application. Int. J. Toxicol. 2012, 31, 228-237. [CrossRef]

47. Hong, H.-A.; Huang, J.-M.; Khaneja, R.; Hiep, L.-V.; Urdaci, M.-C.; Cutting, S.-M. The safety of Bacillus subtilis and Bacillus indicus as food probiotics. J. Appl. Microbiol. 2008, 105, 510-520. [CrossRef]

48. Lakshmi, S.-G.; Jayanthi, N.; Saravanan, M.; Ratna, M.-S. Safety assesment of Bacillus clausii UBBC07, a spore forming probiotic. Toxicol. Rep. 2017, 4, 62-71. [CrossRef] [PubMed]

49. WHO; FAO. Joint FAO/WHO (Food and Agriculture Organization/World Health Organization) Working Group Report on Drafting Guidelines for the Evaluation of Probiotics in Food. WHO and FAO: London, ON, Canada, 2002.

50. Sudha, R.-M.; Sunita, M.; Sekhar, B.-M. Safety studies of Bacillus coagulans Unique IS-2 in rats: Morphological, biochemical and clinical evaluations. Int. J. Probiotics Prebiotics 2011, 6, 43-48.

51. Yang, P.; Zhu, X.; Cao, L.; Cheng, J.; Zheng, Z.; Jiang, S. Safety evaluation of Bacillus cereus isolated from smelly mandarin fish. J. Food Meas. Charact. 2017, 11, 726-735. [CrossRef]

(C) 2020 by the authors. Licensee MDPI, Basel, Switzerland. This article is an open access article distributed under the terms and conditions of the Creative Commons Attribution (CC BY) license (http://creativecommons.org/licenses/by/4.0/). 